Accepted for publication in Language and Literature published by SAGE.

\title{
Exploring new territories in pedagogical stylistics: An investigation of high-school EFL students' assessments
}

\author{
Vander Viana (University of Stirling, UK) \\ Sonia Zyngier (Federal University of Rio de Janeiro, Brazil)
}

\begin{abstract}
The growing number of recent publications on pedagogical stylistics indicates that this area is still of much interest to those who invest in the integration of language and literature. However, evidencebased assessments of pedagogical stylistics are still few and depend mostly on teachers' intuitions. The present study contributes towards filling this gap by examining 28 reflective accounts produced by highschool English as a foreign language (EFL) teenagers who participated in a literary awareness workshop on iconicity. Branching out from pedagogical stylistics, literary awareness is here described as a program which aims at sensitizing students to verbal artistry. The bottom-up analysis of the participants' accounts reveals five main aspects - "applicability," "learning," "materials," "students" and "teaching" - and indicates that the workshop was to a certain degree transformative. Instead of an instrumental approach to language learning, the workshop aimed mostly at consciousness-raising. Students' assessment of the workshop was quite positive, and they linked in-class experience with their lives outside the school. The results indicate that, besides learning a foreign language, the process of reflection has led students beyond the text. We conclude by discussing the implications of the workshop for both pedagogy and research.
\end{abstract}

\section{Keywords}

Pedagogical stylistics, literary awareness, critical pedagogy, English language teaching and learning, English as a foreign language, high school, student appraisal, empirical approach

\section{Introduction}

Since Jakobson (1960) called for the integration of linguistics and poetics, several stylisticians have worked towards combining his theoretical postulations with classroom applications (e.g. Carter and Goddard, 2016; Carter and McRae, 1996; Carter and Nash, 1990; Durant and Fabb, 1990; Hall, 2007; Short, 1989; Simpson, 2004; Toolan, 1998; Watson and Zyngier, 2007; Widdowson, 1975). Among the areas where stylistics can make a useful contribution to pedagogical practice, Hall (2014: 240) includes linguistic creativity and second or foreign language learning. However, despite the growing publications in what has become known as pedagogical stylistics (e.g. Burke et al., 2012, 2016; Carter, 2010; Clark and Zyngier, 2003; McRae, 2001), not much has been done in terms of evidence-based assessments of what actually occurs in the classroom (Fogal, 2015), especially in settings where English is not the first language. In his comprehensive article on the role of literature in foreign language learning and teaching, Paran (2008: 487) argues that the uneasy relationship between language and literature teaching results from the fact that "although there is a strong element of empirical enquiry within stylistics, this empirical approach has not yet extended to a rigorous examination of classrooms and language learning and even less so to L2 learners."

In order to help fill this gap, the present study investigates high-school students' perspectives on the implementation of stylistics in their English as a foreign language (EFL) education. Pedagogically, it innovates by adopting stylistic principles in a context, like in many parts of the world, where EFL education is generally restricted to the teaching/learning of grammar and/or reading skills. As will be discussed below, the present proposal allows students to be sensitized to verbal art and arrive at a more solid position from which they can justify their readings. The approach is transformative in the sense that students have enough room to analyze, pose questions and reflect on major issues linked to their lives while learning meaningful language patterns. Research-wise, this investigation widens the span of pedagogical stylistics since most studies in this field are restricted to university-level education and/or 
to settings where English is spoken as a first language (e.g. Fialho et al., 2011; Hanauer, 2010). It also provides more arguments for evidence-based assessments which use students' reflections as a means of evaluating pedagogical activities.

Indeed, rigorous empirical approaches to pedagogical stylistics are much needed to avoid assessments based on the teacher's intuition of what works and what does not. As noted by Fogal (2015), L2 and EFL classroom applications of stylistics have been underreported and conclusions are rarely supported by evidence. Here, we examine students' appraisals of a literary awareness (henceforth LitAw) workshop in a Brazilian public (i.e. government-sponsored) high-school EFL context. Their appraisals are analyzed through the reflective accounts that these students were asked to write at the end of each of the 10 thematic units in the workshop. ${ }^{1}$

As far as its research design is concerned, the present study could have been conceived in such a way that the classroom situation was as controlled as possible, as is the case in Miall and Kuiken (1994) and Sotirova (2016), to cite just two examples. These types of studies, with high internal validity, have enough evidence to claim that the results observed are due to the experimental treatment they have implemented. However, as Beretta (1986: 305) explains, they "are externally invalid, and their findings cannot be generalised back to the classroom [...] Field research, by contrast, is intended to be of relevance to ESL/EFL instructors." Following Beretta's (1986) suggestion, we decided not to interfere with the regular classroom work. This means that this study is not designed as an experiment in literary reading similar to, for instance, Fialho et al. (2011). Rather, it explores students' reactions during the implementation of a LitAw workshop.

Branching out from pedagogical stylistics, LitAw aims at helping students understand how texts are crafted stylistically and how the language used stirs readers' thoughts and feelings. To check their adaptability, LitAw workshops have been held in different contexts at university level (Fedorova et al., 2006; Zyngier, 1994a, 1994b). ${ }^{2}$ Here, we contemplate another setting: a high-school EFL situation.

This paper is divided into eight main sections. In the following two, we place LitAw within pedagogical stylistics and offer a review of previous empirical work. Section 4 describes the teaching materials used in this study while Section 5 details the demographics of the three groups of participants. The principles of data collection and analysis are described in Section 6, before the empirical findings are presented and discussed in Section 7. This exploratory study generates a series of implications for future work in a currently underexplored area within pedagogical stylistics. These implications will be pointed out in the final section.

\section{Literary awareness (LitAw): theoretical pillars}

LitAw developed from the need to sensitize EFL undergraduates to the language of imaginative texts before they engage in more complex literary studies (Zyngier, 1994a, 1994b). Students learn how linguistic evidence can be used to substantiate interpretations, thus avoiding much of the subjectivity that has characterized literary education. In fact, for decades, the claim-quote approach has found support in models derived from theories such as practical criticism (Richards, 1929) and new criticism (Brooks, 1947), in which teachers instruct students to make a claim and quote a passage to justify their statement. Simply put, students write about what they think the author "wants to say" and use the quotation to justify their argument. Instead, following the tenets of pedagogical stylistics, a LitAw approach will examine how meaning may be derived not from impressions about the text but from the linguistic patterns the writer selects from the range of possibilities available in any given language. LitAw focuses not only on what is done but mostly on how it gets done, and may extend to other creative productions (see Carter and Goddard, 2016; Carter and Nash, 1990; Swann et al., 2011) such as adverts or classifieds. It is assumed that, if students become aware of the workings of language, they may be on 
more solid grounds to produce substantiated interpretations than the claim-quote approach (see Zyngier, 1994a, 1994b).

Situated within stylistics, LitAw also depends on "the close, systematic and linguistically informed study of language use and language choice" (Hall, 2014: 239). LitAw is deeply rooted in functional linguistics as it observes how language is used "(i) as text and as system, (ii) as sound, as writing and as wording, (iii) as structure - configurations of parts and (iv) as resource - choices among alternatives" (Halliday, 2004: 19. For further discussion on functional linguistics as a theoretical basis for LitAw, see Zyngier, 1994a, 1994b).

In addition to functional linguistics, LitAw is inspired by the tenets of reader-response theories, according to which meaning is an event resulting from the reader- text encounter. Reading is an act of personal experience in which the reader responds to elements in the text and, at the same time, uses his/her projections to fill gaps that the text leaves (Iser, 1978: 165). Iser's (1989: 50) definition of reception is thus summarized:

what I call reception is a product that is initiated in the reader by the text, but is molded by the norms and values that govern the reader's outlook. Reception is therefore an indication of preferences and predilections that reveal the reader's disposition as well as the social conditions that have shaped his attitudes. If I wish to assess such a product, I must examine the responseinviting structures of a text, so that I can see how much the actual reader has selected from the potential inherent in the text.

Reader-response critics argue that:

a poem cannot be understood apart from its results. Its "effects" - psychological and otherwise - are essential to any accurate description of its meaning, since that meaning has no effective existence outside of its realization in the mind of a reader (Tompkins, 1980: ix).

It is thus assumed that attribution of meaning begins with the reader's response to the linguistic patterns on the page. According to Miall (2006: 3), "[t]o focus on experience, therefore, is to move decisively beyond the formalism of the New Critics." This encounter varies to a certain extent according to who the reader is and what he/she brings into the text. In line with these statements, LitAw values students' reading reactions. Responses may differ not only because individuals are shaped by distinct psychological, cultural and social conditions but, in the case of EFL students, because their linguistic competences may also vary.

Interest in students' personal experiences links reader-response theories to the view of education proposed by Freire (1980), who values the perspectives of these social actors. He argues that it is much more important to develop students' ability to pose questions and to look for answers based on their own knowledge and culture than to instruct them. In the same light, LitAw holds that learning how to use a toolkit for textual analysis is necessary but not enough. The classroom should turn into a place for collaboration, where problems are raised and possible solutions proposed.

Supported by these three pillars (i.e. functional linguistics, reader-response theories and critical pedagogy), we describe four progressive stages for LitAw workshops.

1. Reacting to linguistic patterns: guided by the tenets of reader-response theories, this stage is a personal, non-transferable experience involving the cognitive and emotional act of reading and responding to the signals on the page (e.g. laughing, crying, feeling anxious or curious), that is, experiencing the text. As Miall (2006: 5) observes, "most ordinary readers pick up a literary text in 
order to gain the experience it offers, not to determine its meaning as a literary critic would." First and foremost, students should enjoy the reading and "live through the text" (Rosenblatt, 1978: 269).

2. Reflecting: at this stage, students are asked to pause and write down why they reacted as they did in the first stage, that is, to determine which textual elements provoked their reactions and what made them feel the way they did. McIntosh (2006: 5) observes that "[r]eflective writing draws students into the text in a natural way and assists them in gaining an understanding of what they are reading."

3. Contextualizing: having responded and reflected on how the text affected them, students are asked to place their experience in a wider system which includes, for instance, setting it in history, thinking of ideological implications of literary tradition, or conventions. This stage will deepen their understanding of the text and of themselves, as proposed by critical pedagogy.

4. Creating: this is the last stage, when students become autonomous in producing their own pieces. An important strategy in learning is to have them work with the pattern under focus and create their own texts. It is an empowering activity, supported by critical pedagogy, in which the students know what they write and why they select certain stylistic resources.

At this point, we would like to stress that the description of theories and strategies that enable readers to arrive at an understanding of verbal artistry is welcome but not sufficient when arguing for a certain method or approach. Empirical assessments of what is actually done have a major role in the process. The next section will review some studies carried out in this direction.

\section{Empirical studies on literary awareness}

To test the usefulness of a LitAw workshop aimed at undergraduates, Pinto (2000) compared the responses of 100 Brazilian university students of English to Blake's "The Lamb" before and after they engaged in 15 workshop units. He collected the participants' pre-workshop reactions and returned them at the end of the workshop with a questionnaire in which he asked whether the students wanted to change their initial analyses and, if so, how. Nearly half of the students (49) expressed their willingness to rewrite their analyses and mentioned specifically the language patterns that they had been sensitized to in the sessions. Out of the 51 remaining participants, 31 did not indicate whether they would change their initial reaction and did not mention any patterns. A group of 20 participants mentioned patterns they had identified but still stated they would not change their previous analyses. Pinto (2000) concluded that most students became more sensitized to stylistic patterns but that their reactions had to be further studied. While Zyngier (1994a) had argued that it was possible to notice the development of students' awareness by comparing pre- and post-workshop tests, Pinto (2000) held that assessing students' sensitization to the literary experience had to consider their self-perception of their progress. He concluded that re-reading and re-interpreting a poem were not sufficient for evaluating the process of literary awareness and proposed that reflection on the work should be followed by self-assessment.

In a follow-up to Pinto's $(2000)$ work, Fialho $(2001,2002)$ addressed the issue of process evaluation and conducted a study in two stages. In the first one, Fialho (2001) analyzed a total of 30 reports produced after three LitAw units (first, fifth and 10th) by 10 randomly selected Brazilian university students. Based on Piaget's (1971) notions of assimilation, accommodation and equilibration, Fialho (2001) observed three categories in the data - factual description, action and abstraction - which she labeled Level 1 (absence of literary awareness), Level 2 (index of awareness) and Level 3 (presence of awareness). She then proceeded to the second stage of her study (Fialho, 2002), which examined three workshops: two experimental groups led by a "sensitized" teacher (i.e. familiarized with LitAw) with and without assistants, and the control group conducted by a "non-sensitized" one (i.e. unfamiliarized with LitAw). Fialho (2002) compared the presence of the three levels identified in her first study in three groups of randomly selected students, each with 16 participants. The findings showed that all participants began the workshop at Level 1 (absence of LitAw) and started to move on to Level 2 (index of awareness) around Unit 5 (out of 10), that is, halfway through the workshop. Level 2 increased in both experimental 
groups and decreased in the control group. Even though all three groups arrived at Level 3, the experimental group led by a sensitized teacher with assistants showed more instances of this level, suggesting that this condition is the best pedagogical scenario.

The three levels of awareness described above were later applied by Zyngier et al. (2007) in their study of an 11-week LitAw workshop aimed at Brazilian undergraduates. The researchers examined data from these students' reflective accounts (11 accounts for each of the 21 participants, totaling 231), classroom observations and field notes. In general terms, the analysis indicated gradual increase in Levels 2 and 3. This means that, over time, a higher number of passages containing initial index or presence of literary awareness were observed in the accounts. Thus, empirical evidence supported the claim that the workshop was successful in triggering and/or increasing awareness.

Moving away from the university setting, LitAw principles were applied to EFL teaching in a Brazilian high-school context. Taking participants' profiles, unit evaluation questionnaires and creative writing as data sources, Zyngier and Viana (2016) observed students' reactions to a LitAw unit. The analysis disclosed students' beliefs about their learning and their assessment of the materials proposed. Among several findings, the profiles showed that, although nearly two-thirds of the participants thought of themselves as good or excellent readers in general, ${ }^{3}$ the same positive self-evaluation did not remain in terms of reading literary texts, where a decreasing cline was noted. After analyzing the participants' answers to the open questions in the unit evaluation questionnaire, the researchers were able to organize them into six categories that indicate the richness and variety of the participants' perceptions. Most students evaluated the unit positively, and they also acknowledged that it enhanced their interpretative skills of literary texts in English.

The works reviewed above point out the value of assessing pedagogical stylistics empirically. The next sections will describe the workshop under focus in this article and detail how it was examined.

\section{Workshop materials}

The LitAw workshop aimed at introducing high-school students to stylistics inductively, that is, getting them involved in activities before concepts were formally introduced. This is in line with the progressive stages of LitAw where reaction precedes reflection (see Section 2). Pedagogically, the teacher acts as a facilitator, aiding the students to formulate concepts in an autonomous way. The students are then expected to assume an active role, taking responsibility for their own learning (Freire, 1980).

Labeled "Playing with form and meaning," the unit under analysis here focused on iconicity. It was the first stylistic concept presented to the high-school participants. The unit followed a four-section structure, namely, (1) "Setting the scene," (2) "Food for thought," (3) "Exploring possibilities" and (4) "Further explorations."

The main objective of the first section was to set the ground for students' reactions to the reading of iconic forms of expression. They were shown a few examples, such as the word "cracked" written as if it were cracked, and were asked to consider how form contributed to meaning. Additional activities invited students to write different types of text (e.g. dialogues and narratives) for which the selected pictorial representations of words could be suitable illustrations. Towards the end of the section, they were encouraged to design a word of their choice where form and meaning were combined. They had to consider their intention and compare it with how their peers interpreted the graphic representation for the word they had chosen.

The second section ("Food for thought") aimed at sensitizing students to the patterns they had seen in the first one. It contained statements on iconicity such as "The graphic display of words contributes to their meaning" and "The visual appeal of written words has been a rich source of exploration in poetry 
and advertising." Following an inductive approach, these statements were only made after the students had arrived at these conclusions themselves. The participants were then asked to look for examples of iconicity in magazines, posters, etc. so that they realized how the pattern was present in their everyday lives.

In the third section ("Exploring possibilities"), the students analyzed a range of different texts (e.g. ads, book covers, headlines), thus becoming aware of creative uses of everyday language (see Section 2). The exercises engaged them in multimodal analyses, where they could consider the effectiveness of the graphic displays in each type of text and explain how they contributed to meaning making. Here, the students completed activities that were aimed at contextualizing, that is, the third LitAw stage (see Section 2).

The final section ("Further explorations") offered the most advanced tasks. The texts were longer than the ones in the previous sections (e.g. a text-rich ad and the opening page of a magazine article) or more challenging (e.g. a concrete poem). The participants were asked to think of associations between different texts and consider the layout. The most important part of this section was its focus on creation, the fourth stage in LitAw (see Section 2). After responding, reflecting and contextualizing, the students were invited to produce their own poems and explain their processes of creation. (For a more detailed description of the materials and illustrations, see Zyngier and Viana, 2016.)

\section{Participants}

Three LitAw workshop groups were held: one per high-school year. ${ }^{4}$ Altogether, 40 students were involved in the pedagogical experience: 12 in the first year, 15 in the second year and 13 in the third year.

The analysis presented in this article abides by the principle of analytical comprehensiveness: a decision was made to analyze all the data available. Out of the 40 participants, only 28 handed in their written reflective accounts on the LitAw unit on iconicity (see Table 1). There are two reasons for the mismatch between the total number of participants and that of reflective accounts: (1) some students only chose the LitAw workshop near or at the end of the first unit (i.e. the one on iconicity); (2) all the students were free to decide whether or not they would hand in their reflective accounts. ${ }^{5}$

Table 1: Participant breakdown

\begin{tabular}{|l|l|l|l|l|}
\hline \multirow{2}{*}{ Datasets } & \multicolumn{3}{c|}{ Workshop group } & \multirow{2}{*}{ Total } \\
\cline { 2 - 5 } & $\mathbf{1}^{\text {st }}$ year & $\mathbf{2}^{\text {nd }}$ year & $\mathbf{3}^{\text {rd }}$ year & \\
\hline Reflective accounts (unit on iconicity) & 9 & 9 & 10 & 28 \\
\hline Profile questionnaires & 9 & 9 & 8 & 26 \\
\hline
\end{tabular}

Before the first LitAw workshop session, all students were invited to fill out a profile questionnaire in their first language containing 28 questions on their socio-economic profile, educational background and English language learning experience (see Zyngier and Viana, 2016). Without this profile questionnaire, one would necessarily have to depend on the teacher's intuitive perceptions of the students' demographics, which would not be thorough and entirely reliable. As indicated in Table 1, two third-year students who handed in their reflective accounts had not filled out their profile questionnaires either because they joined the workshop at a later date or because they were absent when the questionnaire was administered. However, following the principle of analytical comprehensiveness, we decided not to discard their reflective accounts. For this reason, we describe the demographics of 26 students in the present section and report on the findings of 28 reflective accounts in Section 7.

The demographics for each of the workshop groups did not differ considerably. Overall, there was a balance between male (15) and female (11) participants. In each workshop group, the sexes were equally 
divided except for the third-year group (six males, two females). In relation to their ages, as expected, there was a steady increase in the average age per workshop group: 15 in the first year, 16 in the second year and 17 in the third year.

In terms of their English language education, most participants had had between four and seven years of English at school (the number of years would depend on whether they were a first-, second- or thirdyear high-school student). Since the Brazilian education system requires nine schooling years before they move on to high school, most participants started studying this subject in the sixth year.

Besides learning English in school, most participants had studied English at private language institutes. The only exceptions were one participant who did not answer this question and another one who stated not having attended a private language institute. The length of study at these institutes varied considerably from one to nine years.

The discrepancy in EFL study experience is reflected in the participants' self-assessed English proficiency. One of the questions in the profile questionnaire asked them to indicate their proficiency levels by choosing one out of five labels with which they were familiar - i.e. elementary, intermediate, postintermediate, advanced or fluent. The use of these labels was aimed at ensuring that the participants would not find it difficult to answer this question. ${ }^{6}$ Figure 1 illustrates the results of this self-assessment.

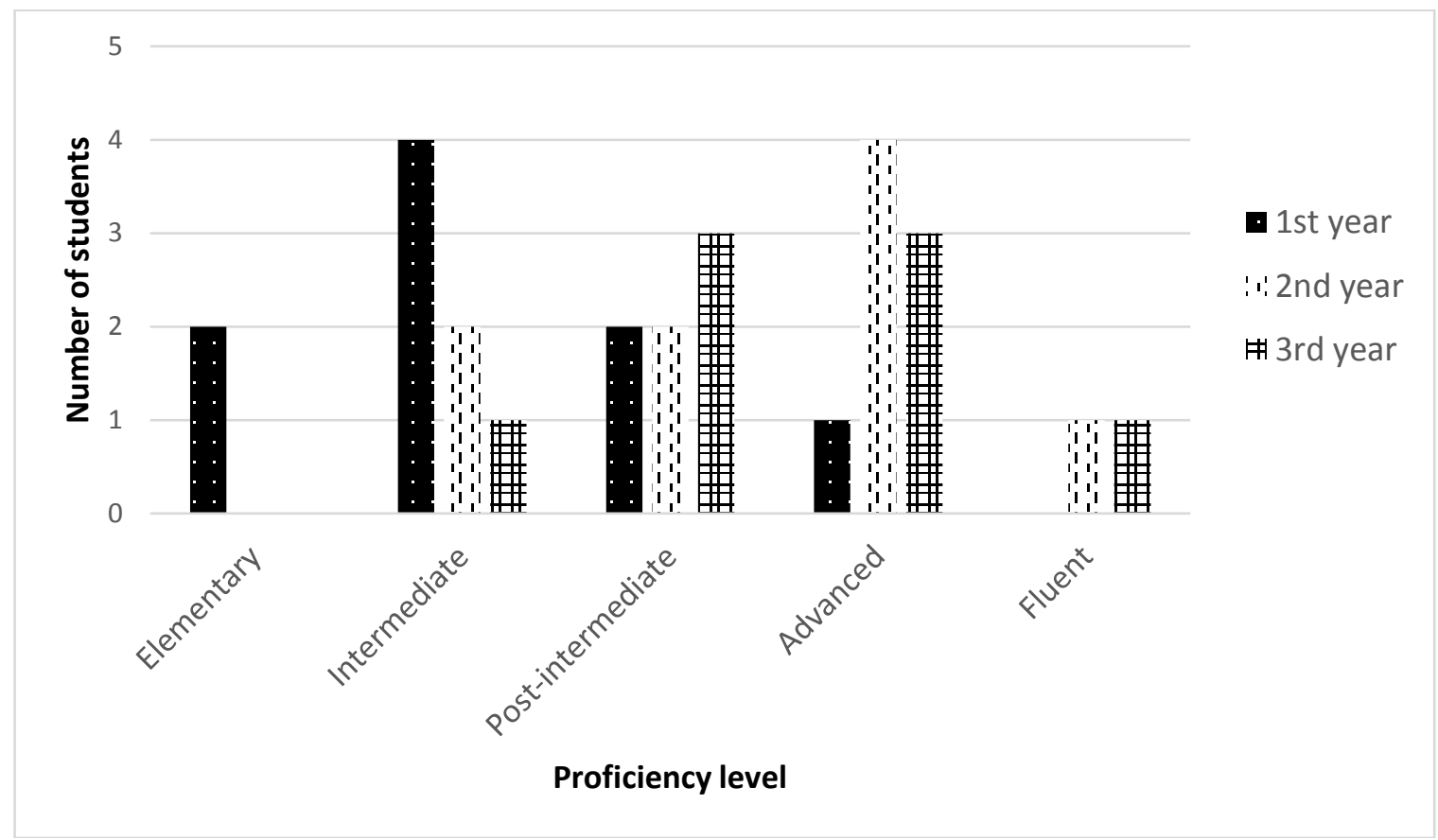

Figure 1: Participants' self-assessed English proficiency level

According to Figure 1, the students' English language proficiency was heterogeneous. When the profiles are considered per high-school year, it is clear that the first-year students believe they have lower English proficiency levels than those in the second and third years. Most participants in the latter two workshop groups identified their command as either post-intermediate or advanced.

It is important to note that the only placement that the students had undergone in this high school was whether they knew no/little English or whether they had some knowledge of this language. Only those in the latter category were allowed to join one of the thematic workshops (the two options on offer at the time were movie or LitAw workshops). The students' self-assessment of their proficiency level was important from a pedagogical viewpoint as the teacher had to deal with diverse levels within and 
between groups. From a research perspective, this self-assessment was essential for the interpretation of some findings (see Section 7).

The 26 students who answered the profile questionnaire mentioned that they had had prior experience interpreting literary texts in their mother tongue. However, only eight said they had analyzed literary texts in English, five of whom were in the second year of high school. While some analytical skills can be transferred from one language to the other (e.g. perceiving repetitions, recognizing figures of speech), the activities proposed in the workshop were still a novelty to most students.

In the profile questionnaire, the participants were also asked to rate their reading appreciation and performance. With regard to the former, more than half stated that they either loved or liked reading, while one-fifth indicated their indifference. When asked to self-assess their performance as readers in general, nearly half of the students claimed to be good readers. However, this positive stance changed when they were asked to rate their performance as readers of literary texts: half of the participants rated their performance as average.

This high-school LitAw workshop was facilitated by a teacher who had been working for one semester at this institution before the start of the workshop. As usual for temporary workers, this school required the teacher to undergo a selection process involving the examination of the résumé and an interview. At the time, the teacher had a first degree in English Language and Literature and was undertaking the second (and final) year of a Master's in Language Studies. This professional can be described as a nonsensitized teacher (see Section 3). However, supervision had been provided to the teacher participant by the proponent of LitAw, who had also taken the lead in designing the workshop materials.

\section{Methods}

The following subsections describe the steps taken for the assessment discussed in this article. The procedures for both data collection and data analysis will be detailed below.

\subsection{Data collection}

The unit on iconicity lasted for six 50-minute sessions over a period of three weeks, after which the students were asked to write a reflective account. As Boud et al. (1996: 33) argue, "[r]eflection is an important human activity in which people recapture their experience, think about it, mull it over and evaluate it." The link between reflection and learning, also proposed by critical pedagogy (see Section 2), has been thoroughly discussed in the literature, which suggests that reflection leads to learning (e.g. Boud et al., 1996; Ertmer and Newby, 1996; McIntosh, 2006; Moon, 1999).

The reflective accounts were written in English for a number of reasons. First, the LitAw workshops were offered to EFL students who needed to be given opportunities to practice their command of this language. Not only did the accounts provide these students with a chance to enhance their writing skills in a personalized way (i.e. they were to write about their own experiences), but the reflection task was also seen as a way of consolidating their learning. The decisions about the type of writing and the language to be used were made by the teacher, who then gave students extensive feedback on their writing.

The choice of the English language for the reflective accounts also suited the present study in that we did not want to interfere with the teacher's pedagogical choices and/or to force participants to write extensively on their experience for research purposes, which would add to their already busy high-school schedule. Besides, as students had been requested to answer an evaluation questionnaire in their mother tongue (see Zyngier and Viana, 2016), the task of writing their reflections in English provided them with ample room for considering their learning experience in a different language and allowed the researchers to compare both instruments. 
Realizing that the production of reflective accounts would be a novelty in this context, the teacher offered some guidelines. Opinions had to be justified, and the accounts needed to contain at least four paragraphs (minimum of 50 words in each) in which they would write about the unit, detail one or more sessions, explain the reason for their choice and discuss the relevance of the unit.

These accounts were produced at home. ${ }^{7}$ One week after the end of each unit, the students were expected to email their reflective accounts to the teacher, who then graded the texts as required in this high-school context. The holistic evaluation adopted, however, was solely based on language use. Marking rubrics consisted of five criteria (i.e. meaningful statements, accurate use of structures, vocabulary appropriate to the level, coherent organization of ideas, and mechanics), each of which was graded in a Likert scale ranging from one (needs improvement) to five (excellent). As can be seen in the rubrics, the criteria did not consider content, a point which was explicitly made in written (i.e. in the guidelines that were distributed in the first session ${ }^{8}$ ) and spoken modes (e.g. in the sessions where the teacher explained the marking rubrics to be used). The students were encouraged to be frank, and they were told in the first workshop session that this would not affect their grades.

At the end of the school year, the teacher requested the students' permission to use their reflective accounts for research purposes. By the time the data were collected, the students' final year-long averages had already been disclosed, so they knew that their decision to participate in the research would not affect their grades. Besides, as it was the last year that teacher worked at the school, the participants were also aware that their opinions would not bring any harm to them in their future highschool years. A consent form was then handed to each individual, who was asked either to complete it or to leave it in blank. The consent forms were placed in a sealed envelope, which was only opened by the teacher after the workshop session. In the end, all the students consented to the use of their reflective accounts for research purposes. The electronic copies submitted by the students were shared by the researchers and analyzed, as discussed in the following subsection.

\subsection{Data analysis}

The analytical procedure adopted in this exploratory field study followed a five-step approach. Initially, both researchers read the reflective accounts from one of the LitAw workshop groups and categorized the reflections bottom-up. This inductive approach prioritized what the students had written about. The second step consisted in comparing the two taxonomies proposed by the researchers, who then agreed on a final list of categories. Later, one of the researchers analyzed the data qualitatively, revisiting the previous analysis. This third step was carried out with the help of NVivo, a computer program which assists the coding of qualitative data. In the fourth step, the other researcher read through the classified excerpts, checking the analysis for both accuracy and consistency. Finally, any debatable categorization was discussed until consensus was reached.

At the onset, the researchers decided that purely descriptive fragments in the reflective account would not be classified. Five analytical categories emerged from the bottom-up analysis of students' written reflections, as summarized in Table 2.

Table 2: Five analytical categories

\begin{tabular}{|l|l|}
\hline Category & Content \\
\hline Applicability & $\begin{array}{l}\text { Discussion on the relevance of the unit to students' lives beyond the EFL } \\
\text { classroom setting (i.e. the importance of the unit to their education, life and } \\
\text { work) }\end{array}$ \\
\hline Learning & $\begin{array}{l}\text { Reflection on what was or was not learned as well as what facilitated or } \\
\text { hindered learning }\end{array}$ \\
\hline
\end{tabular}




\begin{tabular}{|l|l|}
\hline Materials & $\begin{array}{l}\text { Evaluation of the materials used in the workshop sessions (e.g. the works of } \\
\text { art created) }\end{array}$ \\
\hline Students & Self-assessment or assessment of peers' participation in the sessions \\
\hline Teaching & $\begin{array}{l}\text { Consideration of the teacher's facilitator role in the workshop (e.g. the } \\
\text { teaching strategies employed) }\end{array}$ \\
\hline
\end{tabular}

These five categories could be either positive or negative. They were also attributed subdivisions. For instance, in relation to "learning," the students discussed (a) the topic of the unit, (b) the lack of assimilation of key topics, (c) the collaborative nature of their learning and (d) language learning. Due to limited space, in this article we focus only on the main categories and their respective values (i.e. positive or negative).

The categories in Table 2 reveal that the participants put into practice some of the precepts of critical pedagogy. They became the critics of their own work and that of the other participants (the teacher included) and considered how their classroom experiences could also be applied to their lives outside school.

It should be pointed out that the analytical process was not straightforward with a one-to-one correspondence between categories and fragments. As is the case in qualitative data analysis, any fragment could be ascribed to more than one category depending on what the participants intended to convey.

Once the fragments had been categorized, NVivo automatically quantified their frequency. This quantification revealed the most recurrent topics in the accounts, as discussed in the following section.

\section{Results}

The 28 reflective accounts totaled 266 references (or continuous textual fragments), which were assigned to one of the five analytical categories (see Section 6.2). A breakdown of the data can be found in Table 3. For each combination of category and value, two totals are presented: the number of sources (i.e. the different reflective accounts in which the fragments were found) and of references (i.e. the continuous textual excerpts which have been found in the reflective accounts). The number of sources $(\mathrm{N}=28)$ was known prior to the analysis: it corresponds to the number of reflective accounts analyzed (i.e. one per student). However, the number of references $(\mathrm{N}=266)$ depended on what the participants wrote and how they did so. Therefore, it could not be anticipated.

Table 3: Number of sources and references per category and value

\begin{tabular}{|c|c|c|c|c|c|}
\hline \multirow{3}{*}{ Categories } & \multirow{3}{*}{ Values } & \multirow{3}{*}{$\begin{array}{l}\text { Sources } \\
(\mathrm{N}=\mathbf{2 8})\end{array}$} & \multicolumn{3}{|l|}{ References } \\
\hline & & & \multirow{2}{*}{$\begin{array}{l}\text { Per category and } \\
\text { value } \\
\text { Raw }\end{array}$} & \multicolumn{2}{|c|}{ Per category } \\
\hline & & & & Raw & Percentage \\
\hline \multirow{2}{*}{ Teaching } & + & 20 & 51 & \multirow{2}{*}{71} & \multirow{2}{*}{$26.69 \%$} \\
\hline & - & 11 & 20 & & \\
\hline \multirow{2}{*}{ Materials } & + & 23 & 52 & \multirow{2}{*}{66} & \multirow{2}{*}{$24.81 \%$} \\
\hline & - & 8 & 14 & & \\
\hline \multirow{2}{*}{ Applicability } & + & 23 & 50 & \multirow{2}{*}{59} & \multirow{2}{*}{$22.18 \%$} \\
\hline & - & 7 & 9 & & \\
\hline \multirow{2}{*}{ Learning } & + & 21 & 49 & \multirow{2}{*}{57} & \multirow{2}{*}{$21.43 \%$} \\
\hline & - & 4 & 8 & & \\
\hline \multirow{2}{*}{ Students } & + & 6 & 6 & \multirow{2}{*}{13} & \multirow{2}{*}{$4.89 \%$} \\
\hline & - & 6 & 7 & & \\
\hline \multicolumn{3}{|l|}{ Total } & 266 & 266 & $100 \%$ \\
\hline
\end{tabular}


The topics that emerged from the students' reflections can initially be interpreted in light of the guidelines provided in the workshop (see Section 6.1). The frequency of "teaching," "applicability" and "learning" might be potentially related to the fact that students had been asked to reflect on, respectively, the sessions (2nd paragraph), the relevance of the unit (4th paragraph) and its content (1st paragraph). However, the students were entirely free to word their reflections in the way that they thought most appropriate. This means they could have used a descriptive pattern to word their experiences, as follows:

This unit's classes followed a basic structure. At first, the teacher would ask us to take a look at one of the booklet's pages, and then we discussed the text or image we saw on that page so we could start doing the exercises. It was given some time for us to finish them, and a new discussion was started, on which we had the chance to compare our answers to everybody else's. ${ }^{9}[3 \mathrm{AL}]^{10}$

The above fragment, found in the second paragraph of 3AL's reflective account, lacks explicit evaluations and, for this reason, was not included in the analysis. The occurrence of categories such as "materials" and "students" also indicates that the guidelines did not straitjacket the participants' reflective accounts. Nowhere had the students been asked to consider these two topics. The data therefore seem to suggest that the participants exercised their agency, tailoring their texts to what they regarded as most important, as supported by critical pedagogy.

An analysis of the references per category in Table 3 shows that the data are, for the most part, well distributed among "teaching," "materials," "applicability" and "learning." Each of them totals approximately one-fourth of the data. The only exception corresponds to the category which comprehends students' self and/or peer evaluation, which accounts for less than $5 \%$ of the data.

In relation to the values, Table 3 shows that the data contain both positive and negative evaluations, with the latter accounting for a smaller proportion of the data (i.e. 58 references or $21.80 \%$ ). The ratio of positive to negative comments varies from 2.6:1 in relation to teaching to 6.1:1 with regard to learning. The only exception relates to the "students" category, where there are more negative evaluations (seven references) than positive ones (six references); however, this is an infrequent category overall. Despite the teacher's perception of some issues in teacher-student interaction during the workshop sessions, the negative aspects mentioned were comparatively few (i.e. around one-fifth of the overall comments). Any problems the teacher may have noticed seem to have been overcome by the teaching quality, the value of the material, the relevance of the sessions and the learning outcome. An alternative explanation would be that the teacher's intuitive perception was primed by the negative reactions of few students. This reinforces the need for empirical studies such as this one so as to avoid sole reliance on teachers' intuitions (Fogal, 2015; Hall, 2007).

Out of the five categories, "teaching" was the one most frequently mentioned - both positively and negatively - and the participants tended to privilege the strategies adopted. They commented on the way the sessions were conducted, the types of interaction facilitated and the pace of the lesson, among other aspects, as illustrated below:

The class which we did a little text related to the word CRACKED was very well conducted. The teacher explained the subject again but gave us freedom and in circle we read our text which was very fun and we could notice others points of view. It was a really nice class. I love it. The class was like a conversation not as a usual class where the student listens and the teacher talks. [2AD] 
This fragment shows that the session departed from the traditional lesson, that is, a narrative type of class in which the teacher talks and the students listen. Instead, a positive reaction to the studentcentered nature of the workshop sessions can be noticed. Here, a more dialogical approach was praised (Freire, 1980).

Most of the negative evaluations in terms of "teaching" referred to the teacher, which shows that the students exercised their freedom to express their opinion and be heard (Freire, 1980). Criticism ranged from mild comments on the teacher's American accent to more acid remarks about how the teacher's attitude was perceived. However, not only were the negative evaluations infrequent overall (see Table $3)$, but harsh comments were even less common. While infrequent critical remarks should not be automatically disregarded, one must not be primed for negativity when this is not widespread within and/or across groups. This is another reason why an empirical assessment of collective response is needed in pedagogical settings.

The second most recurrent category was "materials." Even though the guidelines did not ask students to evaluate this topic, its recurrence indicates they valued it. Positive evaluations centered mostly on the creative aspect of the workshop. This finding indicates that activities that require students' creativity and input can contribute towards a more effective and stimulating class (see Carter, 1996, 2010; Pope, 1995).

Of all the class that we had, my favorite was the one where we had to create a history that used the word cracked. Our group ([three students' names]) create a history about a chicken and its egg. Beyond amused and funny, this exercise was very educative, as we had to create a whole history. [2BH]

To play with this idea was very nice, I really liked to do that, and I even created two poems instead of only one. [3FT]

In these examples, the students evaluate positively the writing of a story based on an iconic representation of the word "cracked" and the production of a concrete poem. These two students, who enjoy reading thoroughly and see themselves as excellent readers of literary texts according to their answers to the profile questionnaires, praise the activities that they were asked to undertake. The excerpt by 3FT shows that this third-year student was so motivated that he went beyond what had been asked, a clear indication of his engagement in the work. In fact, the examples above illustrate to a certain degree that the students enjoyed the exercises that engaged them in "textual intervention" (Pope, 1995) or "transformative text analysis" (Carter, 2010). The latter concept assumes that "noticing is more likely to take place if features of language and textual organization are drawn to a reader's attention as a result of the text having been manipulated in some way" (Carter, 2010: 118). Indeed, the participants realized that what was essential in the workshop was the perception of how language could be worked for effect.

Most of the criticism of the materials related to the topic of the unit and seemed to have been caused by two main factors: the choice of workshop (i.e. some students had to transfer from the video to the LitAw workshop due to class size) and the diverse levels of English proficiency. The latter factor is exemplified in the following excerpt: "I learned only things that I already know" [2CP]. This second-year participant had taken EFL classes at a private language institute for seven years before the start of the workshop and self-evaluated his English proficiency as fluent. He was probably at the higher end of the proficiency continuum in his workshop group (see also Section 5). Offering activities that cater for mixedability classes should be considered more carefully in future LitAw workshops.

The fact that "applicability" appeared quite frequently in the data is not surprising as the guidelines required that the participants write about the relevance of the unit in the fourth and last paragraph of 
their reflective account. However, it should be stressed that, despite the guidelines, less consideration was given to "applicability" (22.18\%) than to "materials" (24.81\%) and "teaching" (26.69\%). This seems to support the view that the guidelines were interpreted as suggestions - not as rules to be followed. Had the students adhered blindly to them, "applicability" would probably be the most frequent category, and no topic other than the ones included in the guidelines would have appeared in their reflective accounts.

Table 3 shows that most participants commented positively on the link between the unit on iconicity and their lives outside the EFL classroom setting. The framing of such connection under a positive light is telling, as in the excerpt below:

This unit made me see things in some advertisement that I had simply never actually seen, like those who try to sell more of some product. [...] It has changed my point of view from bad to worse in relation to midea, since now I see even more capitalism in front of me, but at least I can now see it. [3RA]

This fragment is a clear example of seeing through language (Carter and Nash, 1990), where this thirdyear adolescent shows how he became aware of the power of the media and the influence of capitalism after the unit on iconicity. Not only was he able to identify what had been discussed in the sessions, but he was also in a position to articulate how this knowledge might help him read the world more critically. If this fragment is interpreted alongside this participant's profile questionnaire, we can see that the LitAw workshop was successful in sensitizing 3RA, who had identified himself as an average general reader and a bad literary reader and who reported spending no time reading for pleasure. Notwithstanding the brevity of the workshop (i.e. six sessions over three weeks), the students realized the importance of the classroom experience in their day-today lives. For instance, some were able to articulate the relevance of their learning to the development of their critical thinking (Freire, 1980; Shukri and Mukundan, 2015), as was the case for 3RA.

Conversely, the most frequent negative comments within "applicability" equally related to "life." For instance, a second-year student wrote that "This topic has something in common with our life, but it is not something relevant. [...] My point of view keeps the same" [2CP]. The data from the profile questionnaire for $2 \mathrm{CP}$ contain some controversial results: while the student indicates that he dislikes reading, he states that he spends $1-5$ hours per week reading for pleasure. Different from 3RA's experience, the LitAw workshop did not have the same positive effect on $2 \mathrm{CP}$. Although the latter conceded that the topic relates to life outside the classroom, he believed that the topic was irrelevant, and so his views were unaffected by the workshop.

These clashing views regarding "applicability" stress one key point: it is unlikely that any pedagogical experience will achieve consensus among students. While negative reflections can be quite instructive, it is important to place them in perspective. The negative reflections on applicability were considerably outnumbered by the positive ones (see Table 3).

The fourth most frequent category related to learning, and, in most cases, they referred to the topic of the workshop unit:

[W]e learned how to interpretate pictures to send information using pictures and their different meanings, not necessarily with words. And the most important thing is that we learned how to connect word, picture and its meaning in a way that others can understand. [3SF]

The fact that "learning" only appeared in the fourth position is yet further evidence that the guidelines did not have a restrictive effect. Despite the inclusion of a question on their learning ("What did you 
learn?"), the findings show that the participants saw the guidelines as a springboard for reflection and decided to write on the matters that were most relevant to them.

In addition, the above excerpt by 3SF shows his awareness that communicating in a foreign language goes beyond grammar or vocabulary learning (see Section 2). In a textbook for language analysis, Carter and Goddard (2016: 3) draw attention to the fact that the "increasingly multimodal nature of our modern communication systems takes us beyond any easy or narrow conceptualizations of speech (or sound) and writing (or symbol)." A further example that the students became sensitized to different ways of communicating can be seen in the following excerpt: "I learn a better way to express what I want to say, with many kinds of movements and forms. [...] and I can do poems better now!" [1NM]. For him, the workshop translated into two educational gains: it helped him express himself better and allowed him to sharpen his skills in poetry writing. Overall, not only did the students reflect on their learning, but they also provided the teacher with plenty of evidence of it (for a discussion on students' creative outputs, see Zyngier and Viana, 2016).

Students' concerns about "learning" were mostly directed at lack of novelty. For instance, one participant wrote that "Except for a few new vocabularies, I personally didn't learn anything important, disappointing my expectations on the workshop" [2LD]. Although this second-year high adolescent indicated that he loved reading in the profile questionnaire, he evaluated the LitAw workshop negatively. As he had already had EFL lessons at a private language institute for about five years, he considered that "everything exposed was already part of my extended knowledge (modestly saying, since I have already graduated my English course)." This concern about learning is very similar to the one about the "materials": in both cases, the complaint relates to the challenges of catering for a mixed-ability EFL group. However, given that the evaluation of "learning" was much more positive than negative (see Table 3), there is enough evidence to state that this experience seemed to have been profitable for most students.

The least frequent category referred to self and peers' evaluation which, in a way, threatened the writers' and/or their peers' faces (e.g. "I have not been participating as much as I should been doing. This year I am not dealing with English as I used to, perhaps due to my free time dedicated to others subjects" [3TF]). However, there were also some face-saving remarks (e.g. "but I am trying to do it [write in English] well" [1SB]). The analysis shows only a slight difference between negative and positive values (see Table 3). Given their reduced occurrence, we will refrain from interpreting the data at this stage.

\section{Concluding remarks and implications for future work}

The workshop described in this article has provided a framework for promoting students' awareness of verbal art through their individual and genuine responses to creative texts - literary or not. Theoretically grounded in reader-response theories, functional linguistics and critical pedagogy (see Section 2), the LitAw workshop has innovated pedagogically in at least three ways.

1. It moved away from the traditional focus on language skills and/or systems (e.g. reading and/or grammar). Instead, based on the tenets of functional linguistics, students worked with language features to communicate their opinions, to create their texts and to impact the reader, a novelty in high schools in Brazil and in many parts of the world.

2. In line with critical pedagogy, it fostered a student-centered approach aimed at raising awareness and avoided an instrumental approach to teaching and learning. Neither of these practices are common in the Brazilian educational system and may not be in other contexts either.

3. It dealt with issues which proved to be relevant to the students' experiences outside the EFL classroom.

Instead of simply proposing yet another way in which stylistics can be implemented in the language classroom, the study has also made a number of contributions to research in pedagogical stylistics: 
- it examined the still underexplored high-school EFL context;

- the research design prioritized pedagogical matters, and the classroom was not treated as a laboratory for research experimentation;

- the study evaluated pedagogical practice empirically instead of relying on an impressionistic evaluation;

- assessment was carried out by the students (rather than solely by the teacher), and the use of reflective accounts provided them with enough room to contribute with their perspectives;

- the analytical comprehensiveness guaranteed rigor, and the description of methods allows for replicability, aspects which are much needed in pedagogical stylistics research.

The results reported here indicate that, in addition to experiencing the four stages described in Section 2 (i.e. responding, reflecting, contextualizing and creating), the students also exercised critical thinking, as in the example where the participant writes about the media. While playing with form, layout and language, the participants considered ways in which the patterns could be applied to other contexts, and criticized the pedagogical experience in a few different aspects.

The use of texts such as pop songs, riddles, comic strips, ads and eventually poems in EFL settings is not a novelty. Here, however, the emphasis is on the creative aspect of language or the effect that the text may have on the reader - not on reading, interpreting and learning language structures. The focus was on students' use of English as a foreign language by creating their own texts and voicing their opinions in this language.

More than learning vocabulary and grammar, as in many EFL contexts, the accounts showed that reflecting on their experience has led students beyond the text. They considered how to apply what they had learned to other situations and, in so doing, evaluated its relevance. The reflective accounts worked well as a way of raising students' awareness of what they had (or had not) learned and provided the teacher and the researchers with enough data to see the experience from the students' perspective. In this sense, the descriptions were thicker than the ones obtained from the evaluation questionnaires (cf. Zyngier and Viana, 2016). We conclude that a shift of paradigm from questionnaires to reflection is welcome as reflective accounts may be quite effective in terms of both teaching and research in pedagogical stylistics (see also Boud et al., 1996; Ertmer and Newby, 1996; McIntosh, 2006; Moon, 1999).

To reach a position where one can safely claim the benefits of pedagogical stylistics for other contexts naturally requires further empirical research as this is yet an under-researched topic. If most participants in this study responded positively to a LitAw workshop on iconicity, it must be checked whether they will do so with other language patterns. It is also important to conduct LitAw workshops in other contexts around the world so as to investigate the feasibility of their implementation in high-school EFL education.

In terms of the implications for literary education, additional research is needed to assert whether LitAw can help students live through the literary experience (e.g. Miall, 2006; Rosenblatt, 1978), stimulate them to explore literary texts independently and enjoyably (e.g. Hanauer, 2010) and enable them to justify their understandings without having to look for quotes or critics' opinions to support their arguments (e.g. Jeffries and McIntyre, 2010).

Ultimately, this study has shown that the students had the opportunity to work genuinely with a foreign language, to feel autonomous enough to play with it (Carter, 2010) and to see how the skills they exercised may apply to the world outside the classroom. In this sense, the experience has been transformative (Freire, 1980). In a very short period of time, they felt quite comfortable speaking out in a language that they did not fully command - and were heard. We agree with Paran (2008: 471) that empirical pedagogical stylisticians are needed: 
because of the way these researchers focus on how learners as language learners are able to interact with the text, and on how literary texts influence classroom interaction. They also illustrate with data from the lessons themselves the learners' engagement with literature and the benefits that accrue to them.

This has been the point of this article. From the evidence reported here, we can state that pedagogical stylistics in this specific high-school EFL environment has helped students to read the text and the world.

\section{Acknowledgements}

We are grateful to two anonymous reviewers and to Olivia Fialho for their insightful comments on an earlier version of this article.

\section{Declaration of Conflicting Interests}

The author(s) declared no potential conflicts of interest with respect to the research, authorship, and/or publication of this article.

\section{Funding}

The author(s) received no financial support for the research, authorship, and/or publication of this article.

\section{Notes}

1. In this study, we use the word "workshop" to refer to the type of meeting held with the students throughout the academic year. The workshop was conducted with different cohorts of students, which are referred to as "workshop groups." This high-school workshop on LitAw consisted of 10 units dealing with different stylistic patterns (e.g. iconicity, irony, metaphor). Each unit was covered in a number of sessions. The unit on iconicity, which is the focus here, lasted for six 50-minute sessions.

2. In Brazil, the workshop has been adapted for students from primary to university level and from different social settings. In Ukraine, the workshop has been delivered to postgraduate students and teachers from Kiev and Horlivka.

3. The question referred to reading in general, that is, reading any text type except for literary ones, which were the focus of a separate question.

4. High schooling in Brazil lasts for three years.

5. While the first group of students could decide whether or not to hand in the reflective account without any penalty, the second group was awarded a zero for the reflective account (see Section 6.1 for an explanation of the marking criteria).

6. Self-assessment of proficiency may be problematic. The only possibility of overcoming this potential problem would be to resort to a standardized test taken by all the students. However, this would be outside the scope of this study. Our aim is not to identify the students' proficiency level. Instead, this is simply reported here as background information to help discuss the findings. The use of a standardized test would also go against the methods adopted in the present study since we did not aim to implement an experimental research design.

7. There was only one exception: the third-year workshop group was allowed some time to start the planning/drafting of their reflective account in one of the sessions, but most of the writing was undertaken at home.

8. In the part dedicated to the correction of the reflective accounts, the guidelines state that "As opinions will not be evaluated here, it is expected that the reflective accounts are written in a sincere way. The evaluation will concentrate solely on use of English."

9. The excerpts from students' reflective accounts have not been edited in any way. They are reproduced in this article as they were written by the participants. 
10. The accounts are identified by a three-digit sequence containing one number and two letters. The number refers to the student's high-school year, and the letters are a unique anonymous identifier for each of the students. This means that 3AL refers to the third-year student who has been labeled AL.

\section{References}

Beretta A (1986) A case for field-experimentation in program evaluation. Language learning 36(3): 295309.

Boud D, Keogh R and Walker D (1996) Promoting reflection in learning: A model. In: Edwards R, Hanson $A$ and Raggatt $P$ (eds) Boundaries of Adult Learning: Adult Learners, Education and Training. Abingdon: Routledge, pp.32-56.

Brooks C (1947) The Well Wrought Urn. New York: Harcourt Brace.

Burke M, Csábi S, Week L, et al. (eds) (2012) Pedagogical Stylistics: Current Trends in Language, Literature and ELT. London and New York: Continuum.

Burke M, Fialho $O$ and Zyngier S (eds) (2016) Scientific Approaches to Literature in Learning Environments. Amsterdam: John Benjamins.

Carter R (1996) Look both ways before crossing: Developments in the language and literature classroom. In: Carter R and McRae J (eds) Language, Literature \& the Learner: Creative Classroom Practice. Essex: Addison Wesley Longman Limited, pp.1-15.

Carter R (2010) Issues in pedagogical stylistics: A coda. Language and Literature 19(1): 115-122.

Carter R and Goddard A (2016) How to Analyse Texts: A Toolkit for Students of English. Oxon: Routledge.

Carter R and McRae J (eds) (1996) Language, Literature \& the Learner: Creative Classroom Practice. Essex: Addison Wesley Longman Limited.

Carter R and Nash W (1990) Seeing Through Language. Oxford: Basil Blackwell.

Clark U and Zyngier S (2003) Towards a pedagogical stylistics. Language and Literature 12(4): 339-351.

Durant A and Fabb N (1990) Literary Studies in Action. London and New York: Routledge.

Ertmer P and Newby TJ (1996) The expert learner: Strategic, self-regulated, and reflective. Instructional Science 24(1): 1-24.

Fedorova Y, Ivanyuk L, Korolchuk V, et al. (2006) The Catchers in the Rhyme. Kiyv: Kiyv National Linguistic University.

Fialho O (2001) Aspectos cognitivos no processo de conscientização literária [Cognitive aspects in the process of literary awareness]. In: Zyngier S, Pinheiro P and Figueiredo RB (eds) Conhecimento \& imaginação: Coletânea dos trabalhos do I ECEL [Knowledge \& Imagination: Collection of Works from the 1st ECEL]. Rio de Janeiro: Faculdade de Letras, Setor de Publicações da Faculdade de Letras da UFRJ, pp.51-57.

Fialho O (2002) A influência do professor e do monitor no processo de conscientização literária [The influence of the teacher and the tutor in the process of literary awareness]. In: Zyngier $\mathrm{S}$ and Valente C (eds) Fatos e ficções: Estudos empíricos da literatura [Facts and Fictions: Empirical Studies of Literature]. Rio de Janeiro: Setor de Publicações da Faculdade de Letras da UFRJ, pp.163-178.

Fialho O, Zyngier S and Miall D (2011) Interpretation and experience: Two pedagogical interventions observed. English in Education 45(3): 236-253.

Fogal G (2015) Pedagogical stylistics in multiple foreign language and second language contexts: A synthesis of empirical research. Language and Literature 24(1): 54-72.

Freire P (1980) Conscientização [Conscientization]. São Paulo: Moraes.

Hall G (2007) Stylistics in second language contexts: A critical perspective. In: Watson G and Zyngier S (eds) Literature and Stylistics for Language Learners: Theory and Practice. Basingstoke: Palgrave Macmillan, pp.3-14.

Hall G (2014) Pedagogical stylistics. In: Burke M (ed.) The Routledge Handbook of Stylistics. London and New York: Routledge, pp.239-252. 
Halliday MAK (2004) An Introduction to Functional Grammar. Revised by Christian M.I.M. Matthiessen. 3rd edition. Oxford and New York: Hodder Arnold.

Hanauer D (2010) Poetry as Research: Exploring Second Language Poetry Writing. Amsterdam: John Benjamins.

Iser W (1978) The Act of Reading: A Theory of Aesthetic Response. Baltimore: Johns Hopkins University Press.

Iser W (1989) Prospecting: From Reader Response to Literary Anthropology. Baltimore and London: The Johns Hopkins University Press.

Jakobson R (1960) Linguistics and poetics. In: Sebeok TA (ed.) Style in Language. New York: Wiley, pp.239-252.

Jeffries L and McIntyre D (2010) Stylistics. Cambridge: Cambridge University Press.

McIntosh J (2006) Enhancing engagement in reading: Reader response journals in secondary English classrooms. Language and Literacy 8(1): 1-11.

McRae J (ed.) (2001) Reading beyond Text: Processes and Skills. CAUCE. 24. Sevilla: Universidad de Sevilla.

Miall DS (2006) Literary Reading. New York: Peter Lang.

Miall DS and Kuiken D (1994) Foregrounding, defamiliarization, and affect: Response to literary stories. Poetics 22(5): 389-407.

Moon JA (1999) Reflection in Learning and Professional Development: Theory \& Practice. London: Koogan Page.

Paran A (2008) The role of literature in instructed foreign language learning and teaching: An evidencebased survey. Language Teaching 41(4): 465-496.

Piaget J (1971) Genetic Epistemology. New York: W.W. Norton.

Pinto MO (2000) Construtos pós-processuais e conscientização literaria [Post-processual constructs and literary awareness]. MA Dissertation, Federal University of Rio de Janeiro, Brazil.

Pope R (1995) Textual Intervention: Critical and Creative Strategies for Literary Studies. London: Routledge.

Richards IA (1929) Practical Criticism. London: Kegan Paul.

Rosenblatt $L$ (1978) The Reader, the Text, the Poem: The Transactional Theory of the Literary Work. Carbondale, IL: Southern Illinois University Press.

Short M (1989) Reading, Analysing and Teaching Literature. London: Longman.

Shukri NA and Mukundan J (2015) A review on developing critical thinking skills through literary texts. Advances in Language and Literary Studies 6(2): 4-9.

Simpson P (2004) Stylistics: A Resource Book for Students. London and New York: Routledge.

Sotirova V (2016) Empirical stylistics as a learning and research tool. In: Burke M, Fialho $O$ and Zyngier $S$ (eds) Scientific Approaches to Literature in Learning Environments. Amsterdam: John Benjamins, pp.227-252.

Swann J, Pope R and Carter R (eds) (2011) Creativity in Language and Literature: The State of the Art. Basingstoke and New York: Palgrave Macmillan.

Tompkins JP (1980) An introduction to reader-response criticism. In: Tompkins J (ed.) Readerresponse Criticism: From Formalism to Post-structuralism. Baltimore: Johns Hopkins University Press, pp.ix-xxvi.

Toolan M (1998) Language in Literature: An Introduction to Stylistics. London: Arnold.

Watson $G$ and Zyngier S (eds) (2007) Literature and Stylistics for Language Learners: Theory and Practice. Hampshire and New York: Palgrave Macmillan.

Widdowson HG (1975) Stylistics and the Teaching of Literature. London: Longman.

Zyngier S (1994a) At the crossroads of language and literature: Literary awareness, stylistics and acquisition of literary skills in an EFLit context. PhD Thesis, University of Birmingham, UK.

Zyngier S (1994b) Introducing literary awareness. Language Awareness 3(2): 95-108. 
Zyngier S and Viana V (2016) Literary awareness in a high-school EFL learning environment: An empirical evaluation. In: Burke M, Fialho $\mathrm{O}$ and Zyngier S (eds) Scientific Approaches to Literature in Learning Environments. Amsterdam: John Benjamins, pp.271-302.

Zyngier S, Fialho $O$ and Rios PAP (2007) Revisiting literary awareness. In: Watson G and Zyngier S (eds) Literature and Stylistics for Language Learners: Theory and Practice. Basingstoke: Palgrave Macmillan, pp.194-209.

\section{Author biographies}

Vander Viana is a lecturer in TESOL and Applied Linguistics and the program director of the PhD in TESOL Research at the University of Stirling, UK. His research/teaching interests include TESOL, corpus linguistics, (academic) discourse analysis and applied linguistics. He is the co-founder/co-chair of the Corpus Linguistics in Scotland (CLiS) Network (www.stir.ac.uk/clis), serves on the editorial board of international journals (e.g. Corpus Pragmatics and TESOL Journal) and has a track record of public funding (e.g. British Academy and British Council). His list of publications includes the co-editing of Perspectives on Corpus Linguistics (John Benjamins, 2011) and Literary Education and Digital Learning: Methods and Technologies for Humanities Studies (IGI Global, 2010).

Sonia Zyngier is an adjunct professor at the Federal University of Rio de Janeiro, where she also worked as director of Cultural Affairs and Continuing Education. She was on the Board of PALA and IGEL for many years and is a member of both national and international editorial boards of several journals. She has authored numerous papers on literary awareness, stylistics, and empirical research in literary education. She has contributed to the Elsevier Encyclopedia of Language and Linguistics with an article on pedagogical stylistics (2005). Her publications include Literature and Stylistics for Language Learners (2006) edited with Greg Watson, and Scientific Methods for the Humanities (2012), written jointly with Willie van Peer and Frank Hakemulder. She has also edited Language, Discourse, Style: Selected Works of John McH. Sinclair (2016). Currently, she co-edits the Linguistic Approaches to Literature series (John Benjamins). 